\title{
Potencial de briquetagem de resíduos florestais da região do Seridó, no Rio Grande do Norte
}

\author{
Rosimeire Cavalcante dos Santos ${ }^{1}$, Angélica de Cássia Oliveira Carneiro², Renato Vinícius Oliveira Castro², \\ Alexandre Santos Pimenta ${ }^{1}$, Ana Flávia Neves Mendes Castro², Itaragil Venâncio Marinho³, Mariana Almeida Villas Boas² \\ ${ }^{1}$ Universidade Federal do Rio Grande do Norte (UFRN), Departamento de Agropecuária, Av. Sen. Salgado Filho, 3000, CEP 59078-970, Natal, RN, Brasil \\ ${ }^{2}$ Universidade Federal de Viçosa (UFV), Departamento de Engenharia Florestal, Av. Peter Henry Rolfs, s/n, CEP 36570-000, Viçosa, MG, Brasil \\ ${ }^{3}$ Emater/PB - SOS Sertão, Rua Zuza Cabral, 18, CEP 58705-220, Patos, PB, Brasil
}

"Autor correspondente:

meire_caico@yahoo.com.br

Termos para indexação:

Resíduos florestais

Briquetagem

Energia renovável

Região semiárida brasileira

Index terms:

Forest residues

Briquetting

Renewable energy

Semi-arid Brazilian region

Histórico do artigo:

Recebido em 15 jun 2011

Aprovado em $07 \mathrm{dez} 2011$

Publicado em 28 dez 2011

doi: 10.4336/2011.pfb.31.68.285
Resumo - Esse trabalho teve como objetivos avaliar o potencial de aproveitamento de resíduos gerados pela exploração florestal de espécies que ocorrem no semiárido brasileiro na região do Seridó, Estado do Rio Grande do Norte, para a produção de briquetes, determinar as propriedades físicas e mecânicas dos briquetes, correlacionar a densidade da madeira com a densidade após a produção dos briquetes, e a densidade dos briquetes com a resistência à compressão. Foram coletadas 32 árvores (oito espécies com quatro repetições). A avaliação das propriedades físicas e químicas entre as madeiras foram realizadas segundo um delineamento inteiramente casualizado. Para as variáveis relacionadas aos briquetes, adotou-se o mesmo delineamento, com três repetições por espécie, totalizando 24 unidades amostrais. Os briquetes produzidos com a madeira de jurema-preta se destacaram em função dos maiores teores de carbono fixo, poder calorífico, e resistência à compressão plana. Os briquetes produzidos com os resíduos da madeira de imburana apresentaram os piores desempenhos para os parâmetros estudados. Foi observada correlação negativa entre a densidade básica das madeiras e o ganho de densidade relativa aparente dos briquetes e correlação positiva entre a densidade aparente dos briquetes e a resistência à compressão plana.

\section{Potential of forestry residue briquetting of Seridó region species in Rio Grande do Norte State, Brazil}

\begin{abstract}
This study aimed to evaluate the potential use of waste generated by forestry species that occur in semiarid northeastern at Seridó region, Rio Grande do Norte, for the briquettes production, determine the physical and mechanical briquettes properties, and to correlate the wood density with the density after the briquettes production and briquettes density with the compressive strength. Thirty-two trees were collected (eight species with four replications). The wood physical and chemical properties evaluation were held under a completely randomized design. For the variables related to briquette, it was adopted the same design with three replicates for each species, totalizing 24 sampling units. The briquettes produced with jurema-preta wood stood out as a function to higher fixed carbon content, calorific value and higher compressive strength flat. The briquettes made from waste of imburana wood had the worst performances for the studied parameters. It was observed a negative correlation between the wood density and the gain of apparent relative density of the briquettes and a positive correlation between the briquettes density and the compressive strength of flat.
\end{abstract}




\section{Introdução}

O contexto dos dados da matriz energética brasileira e, especialmente, a realidade dos setores doméstico, industrial e comercial da região do Seridó e do Estado do Rio Grande do Norte, apontam para a necessidade de intensificar os estudos sobre a utilização da madeira para geração de energia naquela região, como também sobre os principais processos de conversão termoquímica da madeira, em especial aqueles que utilizam resíduos provenientes da exploração florestal, para dar suporte ao uso racional da madeira.

O aproveitamento de resíduos da biomassa florestal irá interferir positivamente nas atividades econômicas ligadas à exploração dos recursos florestais, os quais são responsáveis por uma porcentagem significativa da renda gerada no Estado do Rio Grande do Norte.

Os principais segmentos que utilizam a madeira como fonte de energia, que é a base da produção, são: cerâmicas, caieiras, queijeiras, panificadoras, casas de farinha, olarias, carvoarias, unidades de fabricação de biscoitos caseiros, docerias, alambique, engenhos, mineração, indústrias de torrefação, têxtil, de margarina e de sabão (Agência de Desenvolvimento Sustentável do Seridó, 2008).

As espécies que ocorrem no semiárido brasileiro, onde está localizada a região do Seridó, apresentam, entre outras características, troncos que possuem muitas bifurcações, o que gera uma grande quantidade de resíduos durante a colheita, além de apresentar, de modo geral, grande variação nas faixas de densidade da madeira.

O processo de briquetagem é uma forma indicada para aproveitar resíduos em relação a sua reutilização. Por se tratar de um material com umidade baixa, reduz a biodegradação, além de aumentar a densidade energética do produto compactado (Silva, 2007). Esse processo consiste na aglomeração de partículas por meio de pressão, com auxílio ou não de um aglutinante, permitindo a obtenção de um produto não só compactado, mas também com forma, tamanho e parâmetros mecânicos adequados.

Considera-se que todas as estratégias que resultem em aumento na eficiência de conversão energética, além de trazer alternativas econômicas, representam benefícios ambientais por incentivar a redução na geração de resíduos e de emissões, eliminando os impactos social e ambiental por ela causados. Essas ações promoverão impacto direto nas questões ambientais, especialmente, na demanda pelo corte da madeira. Esse fato vem de encontro à redução da pressão sobre o Bioma Caatinga. Além disso, há necessidade de se obter outras fontes e formas de energia, a partir da biomassa.

Dessa forma, os objetivos desse trabalho foram avaliar o potencial de aproveitamento de resíduos gerados pela exploração florestal de espécies que ocorrem no semiárido brasileiro na região do Seridó, Estado do Rio Grande do Norte, para produção de briquetes, correlacionar a densidade da madeira e o ganho em densidade após a produção dos briquetes e a densidade dos briquetes com a resistência à compressão.

\section{Material e métodos}

Foram utilizados resíduos provenientes da exploração florestal realizada em um povoamento com 20 anos de idade localizado na Fazenda Dominga, Município de Caicó, Estado do Rio Grande do Norte, situado nas coordenadas geográficas 618 ' 55,3" S e 3659 ' 28,8 " W, que compreende uma área total de $2.005,8$ hectares (ha), sendo que destes, 367,9 ha de vegetação nativa de Caatinga estão submetidos ao manejo florestal madeireiro. O material madeireiro explorável refere-se à lenha com destino energético.

A vegetação predominante é caracterizada pela Savana Estépica Arborizada com estratos arbóreo (de árvores baixas providas de acúleos ou espinhos) e gramíneo-lenhoso periódico, com diversas cactáceas e bromeliáceas, e acentuado nível de endemismo, destacando-se os gêneros Aspidosperma, Croton, Mimosa e Spondias (IBGE, 2004), ou Caatinga Arbustiva Arbórea Aberta antropizada, podendo se encontrar nas áreas de difícil acesso (de relevo ondulado regionalmente conhecido por "serras"), Caatinga Arbustiva Arbórea Fechada (Agência Nacional de Águas, 2005).

As espécies foram selecionadas tendo como base o valor de importância, expressa no plano de manejo das áreas, realizada pelo Projeto Sustentabilidade Bioenergética Florestal para as Cerâmicas do Vale Carnaúba/Rio Grande do Norte executado pela Organização Sertaneja dos Amigos da Natureza (SOS Sertão). Foi observado um número médio de 12 bifurcações por árvore, que proporcionou grande volume de resíduos. 
Foram coletados os resíduos do lenho, provenientes da exploração florestal de 32 árvores, referentes a quatro árvores-amostra de oito espécies para avaliação das características físicas e químicas entre as madeiras e para confecção dos briquetes. As espécies estudadas estão na Tabela 1.

Tabela 1. Espécies empregadas na confecção dos briquetes.

\begin{tabular}{ll}
\hline \multicolumn{1}{c}{ Nome vulgar } & \multicolumn{1}{c}{ Nome científico } \\
\hline Jurema-preta & Mimosa tenuiflora (Willd.) Poiret \\
Pereiro & Aspidosperma pyrifolium Mart \\
Marmeleiro & Croton sonderianus Müll.Arg. \\
Catingueira & Caesalpinia pyramidalis Tul. var. pyramidalis \\
Mororó & Bauhinia cheilantha (Bong.) Steud. \\
Imburana & Commiphora leptophloeos (Mart.) J.B.Gillett \\
Jurema-branca & Piptadenia stipulacea (Benth.) Ducke \\
Mofumbo & Combretum leprosum Mart. \\
\hline
\end{tabular}

\section{Determinação da densidade básica da madeira}

Para determinação da densidade básica da madeira, retirou-se de cada árvore-amostra um disco com espessura média de $3 \mathrm{~cm}$. Desses, foram retiradas as cascas e obtidas cunhas opostas, passando pela medula. Fio utilizado o método de imersão em água, descrito por Vital (1984). Os valores foram calculados para cada espécie pela média aritmética das densidades observadas em cada uma das quatro árvores amostradas.

\section{Produção de briquetes}

Para confecção dos briquetes, o material foi processado em moinho martelo para obtenção de partículas de, no máximo, $1,5 \mathrm{~cm}$ de comprimento. Em seguida, foram acondicionadas em câmara climatizada até atingirem umidade em torno de $10 \%$, a qual foi determinada pela diferença de uma massa conhecida de resíduo antes e após a secagem a $103 \pm 2{ }^{\circ} \mathrm{C}$ até massa constante em estufa com controle de temperatura, de acordo com a NBR 7993, da Associação Brasileira de Normas Técnicas (1983). Posteriormente, foram confeccionados briquetes para cada espécie. As análises foram realizadas sob amostragem composta das quatro árvores-amostra, com três repetições por parâmetro estudado.

Os briquetes foram produzidos em briquetadeira de laboratório com prensa pistão da marca Lippel e modelo BL 32. Utilizou-se pressão de 68,9 x 105 N.m² $(1.000$ PSI), temperatura de $120{ }^{\circ} \mathrm{C}$, tempos de aquecimento e resfriamento de 5 minutos e umidade de trabalho de $10 \%$. A massa utilizada em cada briquete foi determinada em função da matriz da briquetadeira e do resíduo proveniente da madeira de menor densidade. A coluna ocupada pelo resíduo possui dimensões equivalentes a $10 \mathrm{~cm}$ de altura e diâmetro de $3 \mathrm{~cm}$. A massa de 20 gramas de partículas ocupou praticamente todo o volume da coluna cilíndrica da briquetadeira.

Após a produção, os briquetes foram acondicionados em câmara climática até atingir a umidade de equilíbrio, nas condições de $65 \pm 3 \%$ de umidade e temperatura de $20 \pm 3{ }^{\circ} \mathrm{C}$, onde permaneceram até atingir massa constante.

\section{Avaliação das propriedades dos briquetes}

A densidade aparente dos briquetes foi determinada pelo método de imersão em mercúrio $(\mathrm{Hg})$, de acordo com a NBR 11941 da Associação Brasileira de Normas Técnicas (2003).

A metodologia utilizada para determinação das porcentagens de carbono, hidrogênio, nitrogênio, enxofre e oxigênio presentes nos briquetes está de acordo com o método do equipamento Analisador Elementar, modelo Vario Micro Cube CHNS-O. O oxigênio foi quantificado ao subtrair 100 do somatório dos elementos analisados. $\mathrm{O}$ analisador utiliza como gás de arraste e ignição o hélio e o oxigênio, respectivamente.

A composição química imediata dos briquetes foi realizada seguindo os procedimentos preconizados pela ABNT NBR 8112 para a determinação dos teores de materiais voláteis, cinzas e carbono fixo, em base seca (Associação Brasileira de Normas Técnicas, 1986), sendo o percentual de carbono fixo determinado pela soma percentual de materiais voláteis e cinzas, decrescido de 100.

Para cálculo do poder calorífico superior, utilizou-se o método da Bomba Calorimétrica Adiabática, de acordo com a American Society for Testing and Materials (1982). Para tanto, pesou-se 0,5 gramas de resíduo absolutamente seco, que foi levado a uma cápsula de aço no interior do equipamento. $O$ procedimento consiste na combustão da massa de resíduo em uma cápsula de aço dentro de um recipiente fechado a vácuo sob pressão de 25 atm de $\mathrm{O}_{2}$.

Para determinação da resistência máxima durante a aplicação de força de compressão, utilizou-se uma máquina de testes universal marca Losenhausen.

$\mathrm{O}$ valor de resistência à compressão foi calculado em função da força de resistência do briquete até a ruptura da carga de tensão. O equipamento aplicou uma força plana na lateral do briquete por meio de pistão com velocidade 
de ensaio pré-estabelecida $\left(6,0 \mathrm{~mm} \mathrm{~min}^{-1}\right)$. O resultado da resistência à compressão foi determinado por um software acoplado ao equipamento. O procedimento de análise está de acordo com a metodologia expressa na NBR 7190 da Associação Brasileira de Normas Técnicas (1997), uma vez que não se tem normas específicas para testes em briquetes.

\section{Análise estatística}

O experimento foi analisado segundo um delineamento inteiramente casualizado, com oito tratamentos (espécies) e quatro repetições (árvores-amostra) para as variáveis relacionadas à madeira, totalizando 32 unidades amostrais. Para as variáveis relacionadas aos briquetes, adotou-se o mesmo delineamento, com três repetições sob amostragem composta das quatro árvoresamostra, totalizando 24 unidades amostrais.

Os dados foram submetidos aos testes de Lilliefors para testar a normalidade, e Cochran para testar a homogeneidade das variâncias. Em seguida, procedeuse à análise de variância pelo teste $\mathrm{F}$, sendo as médias comparadas pelo teste Tukey. Para as variáveis que não apresentaram homogeneidade das variâncias, foi aplicado o teste não-paramétrico de Kruskall-Wallis. Considerou-se sempre o nível de significância de 5\%.

Para confirmar a influência da densidade básica da madeira no ganho de densidade após a briquetagem, bem como o incremento da resistência à compressão plana dos briquetes em função da sua densidade aparente, foi empregado o coeficiente de correlação de Pearson entre os pares dessas variáveis, a 5\% de significância,. Quando estabelecidas correlações significativas, foram elaboradas equações ajustando-se modelos lineares de regressão.

\section{Resultados e discussão}

\section{Determinação da densidade básica da madeira}

Não foi observada homogeneidade das variâncias na avaliação da densidade básica da madeira, e os valores encontrados foram submetidos ao teste não-paramétrico de Kruskall-Wallis (Figura 1).

Os maiores valores médios observados para a densidade básica das madeiras das espécies estudadas no processo de briquetagem foram para o mororó $\left(0,97 \mathrm{~g} \mathrm{~cm}^{-3}\right)$ e para a jurema-preta $\left(0,90 \mathrm{~g} \mathrm{~cm}^{-3}\right)$, enquanto os menores valores foram observados para o pereiro $\left(0,62 \mathrm{~g} \mathrm{~cm}^{-3}\right)$, seguido da imburana $\left(0,29 \mathrm{~g} \mathrm{~cm}^{-3}\right)$.

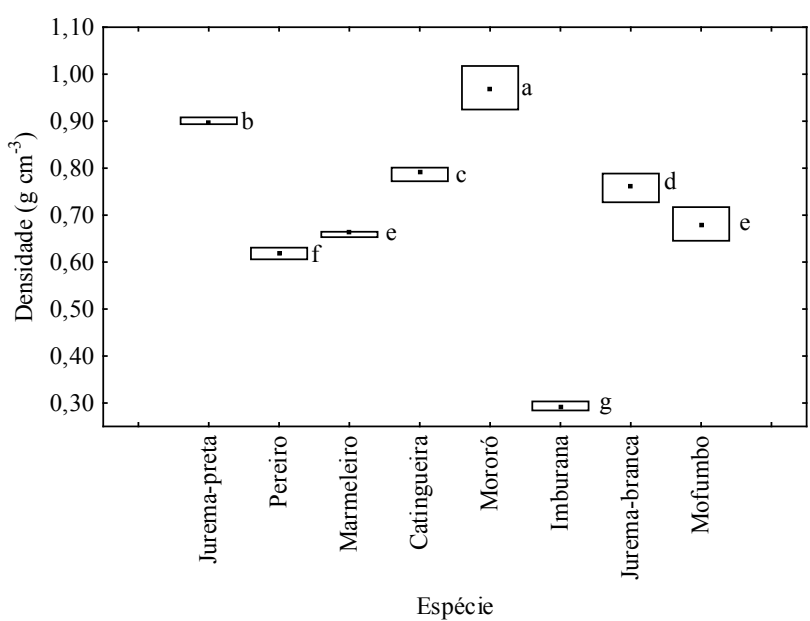

Figura 1. Valores médios para densidade básica da madeira $\left(\mathrm{g} \mathrm{cm}^{-3}\right)$ para as oito espécies. Médias seguidas da mesma letra, não diferem entre si, pelo teste Kruskall-Wallis.

Rodrigues (2010) estudou o emprego de resíduos madeireiros no processo de briquetagem com densidade básica equivalente a $0,67 \mathrm{~g} \mathrm{~cm}^{-3}$. De acordo com Quirino et al. (2005), a produção de briquetes pode ser afetada por uma série de fatores que podem comprometer a eficiência do produto, entre elas as propriedades da matéria-prima, a exemplo da densidade da madeira utilizada como resíduo.

A faixa de densidade das madeiras que geraram os resíduos foi bastante ampla, o que pode ser bem favorável para o processo de briquetagem, se considerada a eficiência do processo no que se refere ao aproveitamento de resíduos. Mesmo que a briquetagem seja aplicada, na maioria das vezes, com o intuito de aumentar a densidade do material, nesse caso, as características das espécies estudadas favorecem o aproveitamento dos resíduos da exploração florestal em função do grande número de bifurcações, de espessuras variadas, observadas em todas as espécies, inclusive nas de maior densidade.

De acordo com Overend (1980), a utilização de resíduos para a geração de energia pode ocorrer em função de três origens distintas: pelo aproveitamento de resíduos urbanos ou resíduos de processos industriais, pelo aproveitamento de resíduos de explorações florestais e agrícolas e pelo plantio de culturas, de curta duração.

Ressalta-se ainda que, sob as condições de variação ampla de densidade do material, haverá, inclusive, a oportunidade de adequação a respeito do gasto energético com eventuais misturas de materiais, o 
chamado processo de produção de briquetes compostos, visto que, resíduos com maior densidade favorecem menores custos no processo de compactação em função do menor gasto energético, o que pode ser inferido de forma oposta para os resíduos de baixa densidade durante o processo de briquetagem. Além disso, a produção de briquetes compostos oferece outra vantagem que é a não dependência de um único tipo de matéria-prima (Rodrigues et al., 2002).

\section{Avaliação das propriedades dos briquetes}

Houve efeito da madeira de origem na densidade aparente dos briquetes, sendo os maiores valores observados para os briquetes confeccionados com resíduos das madeiras de jurema-preta e catingueira $(1,19$ $\mathrm{g} \mathrm{cm}^{-3}$ ) e os menores valores para aqueles confeccionados com a madeira de marmeleiro $\left(1,05 \mathrm{~g} \mathrm{~cm}^{-3}\right)$ (Figura 2).

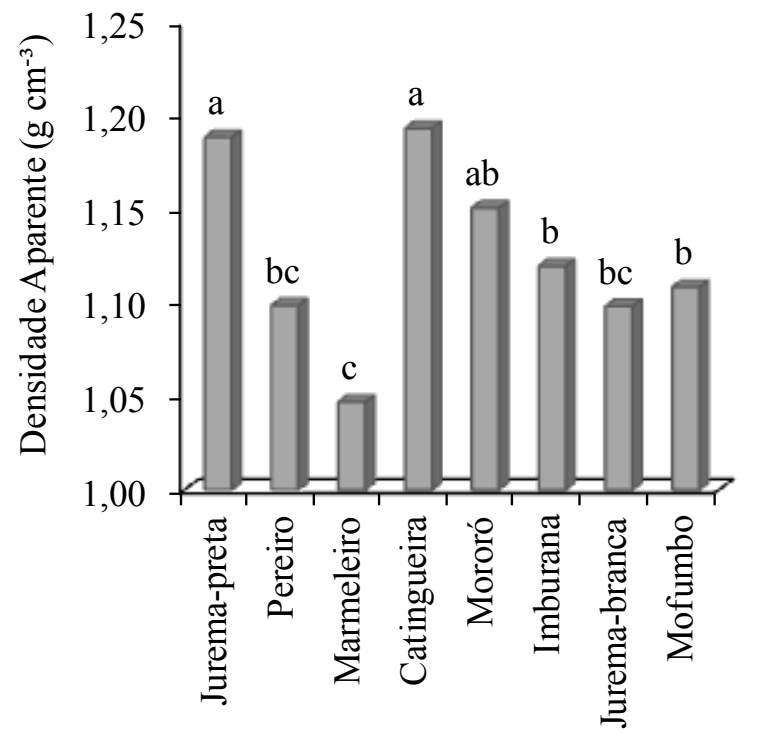

Figura 2. Valores médios para densidade aparente dos briquetes confeccionados a partir das oito espécies. Médias seguidas da mesma letra entre as espécies não diferem entre si, pelo teste de Tukey $(\mathrm{p} \leq 0,05)$.

Esses valores são superiores aos observados por Silva (2007) ao confeccionar briquetes com resíduos madeireiros com densidade igual a $0,51 \mathrm{~g} \mathrm{~cm}^{-3}$. O mesmo foi observado para densidade aparente de briquetes por Paula (2010), com valores que variaram entre 0,85 e 0,90 $\mathrm{g} \mathrm{cm}^{-3}$. Já Rodrigues (2010) encontrou valores médios para essa variável equivalentes a $1,11 \mathrm{~g} \mathrm{~cm}^{-3}$.
O estudo da densidade aparente de briquetes demonstra a viabilidade de estocagem, armazenamento e transporte dos mesmos, visto que maiores valores para essa variável promoverão algumas vantagens nos referidos aspectos, como a concentração de maior energia disponível por unidade de massa do material. Segundo Quirino \& Brito (1991), o uso de briquetes tem como vantagem a ser destacada a economia no transporte quando comparado ao resíduo não briquetado, pois um mesmo volume de briquete pode ter cinco vezes mais energia que a madeira in natura, havendo maior incremento conforme a densidade do material for aumentada.

Dessa forma, infere-se que os briquetes produzidos neste trabalho apresentam faixa de densidade aparente favorável a uma boa logística no que se refere ao fornecimento energético, transporte e armazenamento dos mesmos, o que pode trazer benefícios, especialmente, em relação aos custos. No entanto, deve-se considerar também a distância entre o acesso aos resíduos e o local de produção dos briquetes.

Dentre os valores obtidos para a composição elementar dos briquetes, observa-se que apenas o teor de enxofre (S) não apresentou homogeneidade de variância, e deste modo esses valores foram submetidos ao teste nãoparamétrico de Kruskall-Wallis. Para as demais variáveis analisadas, os valores mostraram-se significativos pela análise de variância (teste $\mathrm{F}, \mathrm{p}<0,05$ ), exceto para o teor de hidrogênio $(\mathrm{H})$ (Tabela 2).

Tabela 2. Valores médios da composição química elementar dos briquetes confeccionados a partir das oito espécies.

\begin{tabular}{llllll}
\hline \multicolumn{1}{c}{ Espécie } & $\mathbf{N ~ ( \% )}$ & $\mathbf{C ~ ( \% )}$ & $\mathbf{H ~ ( \% )}$ & $\mathbf{S ~ ( \% ) *}$ & $\mathbf{O ~ ( \% )}$ \\
\hline Jurema-preta & $1,20 \mathrm{ab}$ & $47,03 \mathrm{ab}$ & $8,34 \mathrm{a}$ & $0,18 \mathrm{a}$ & $45,93 \mathrm{~b}$ \\
Pereiro & $1,32 \mathrm{a}$ & $47,25 \mathrm{a}$ & $8,21 \mathrm{a}$ & $0,07 \mathrm{ab}$ & $45,60 \mathrm{~b}$ \\
Marmeleiro & $1,10 \mathrm{ab}$ & $46,87 \mathrm{ab}$ & $8,00 \mathrm{a}$ & $0,09 \mathrm{ab}$ & $46,09 \mathrm{~b}$ \\
Catingueira & $1,00 \mathrm{ab}$ & $44,70 \mathrm{ab}$ & $8,17 \mathrm{a}$ & $0,08 \mathrm{ab}$ & $48,76 \mathrm{ab}$ \\
Mororó & $0,86 \mathrm{~b}$ & $47,44 \mathrm{a}$ & $9,11 \mathrm{a}$ & $0,03 \mathrm{c}$ & $46,46 \mathrm{ab}$ \\
Imburana & $1,18 \mathrm{ab}$ & $43,85 \mathrm{~b}$ & $8,01 \mathrm{a}$ & $0,12 \mathrm{a}$ & $49,38 \mathrm{a}$ \\
Jurema-branca & $0,85 \mathrm{~b}$ & $46,82 \mathrm{ab}$ & $8,13 \mathrm{a}$ & $0,10 \mathrm{a}$ & $46,48 \mathrm{ab}$ \\
Mofumbo & $1,13 \mathrm{ab}$ & $46,01 \mathrm{ab}$ & $7,80 \mathrm{a}$ & $0,10 \mathrm{a}$ & $46,87 \mathrm{ab}$ \\
\hline
\end{tabular}

Médias seguidas da mesma letra, para uma mesma variável, não diferem entre si, pelo teste de Tukey $(\mathrm{p} \leq 0,05)$. *Médias seguidas da mesma letra não diferem entre si pelo teste Kruskall-Wallis.

Seye et al. (2003) observaram em resíduos madeireiros presença de $\mathrm{C}=48,06 \%, \mathrm{H}=6,03 \%, \mathrm{~N}=0,7 \%$, traços de $\mathrm{S}$ e $\mathrm{O}=45,2 \%$. Paula (2010), ao estudar a briquetagem 
de resíduos madeireiros, observou porcentagens equivalentes a $\mathrm{C}=48,2 \%, \mathrm{H}=6,5 \%, \mathrm{~N}=0,1 \%, \mathrm{~S}=0,2 \%$ e $\mathrm{O}=45,1 \%$. No presente trabalho, maiores teores de carbono foram observados nos briquetes de mororó e pereiro, sem, no entanto, apresentarem diferença significativa dos demais tratamentos, com exceção dos briquetes de imburana, os quais apresentaram menores teores de carbono.

Visando utilização energética, maiores porcentagens de carbono e, em especial, de hidrogênio, são desejados no material combustível, visto que o efeito térmico resultante da combustão de um material é favoravelmente influenciado pelas reações decorrentes da presença dos mesmos. Assim, observa-se que, apesar de menores valores da porcentagem de carbono quando comparado aos trabalhos de Sey et al. (2003) e Paula (2010), maiores porcentagens de hidrogênio foram observadas nos briquetes produzidos com resíduo da exploração madeireira de espécies da Caatinga, indicando que esses possuem altas porcentagens desses elementos. No entanto, vale ressaltar que nos briquetes produzidos com resíduos da madeira de imburana, além de menores porcentagens de carbono, observam-se também altos teores de oxigênio, fato que diminui seu valor combustível.

Destaca-se ainda, na avaliação dos briquetes oriundos das madeiras do semiárido brasileiro, baixos teores de enxofre, o que favorece a utilização dos mesmos sem que haja maiores danos físicos em equipamento utilizados para combustão do material, como também formação de gases prejudiciais à saúde humana e ao meio ambiente. Segundo Cortez et al. (2008), o enxofre se encontra na fração combustível fixa e não combustível (cinzas) do resíduo do material.

De acordo com Rodrigues (2010), os resíduos de madeira normalmente apresentam baixo percentual de nitrogênio, em torno de $0,1 \%$. Destaca-se que os briquetes confeccionados com os resíduos das oito madeiras em estudo apresentaram valores bem superiores ao citado.

Para todas as variáveis estudadas a partir da análise química imediata dos briquetes, os tratamentos foram significativos pela análise de variância (teste $\mathrm{F}, \mathrm{p}<0,05$ ) (Tabela 3).
Tabela 3. Valores médios das porcentagens de matérias voláteis (MV), cinzas e carbono fixo presentes nos briquetes confeccionados a partir das oito espécies.

\begin{tabular}{lccc}
\hline \multicolumn{1}{c}{ Espécie } & $\begin{array}{c}\text { MV } \\
(\%)\end{array}$ & $\begin{array}{c}\text { Cinzas } \\
(\%)\end{array}$ & $\begin{array}{c}\text { Carbono Fixo } \\
(\%)\end{array}$ \\
\hline Jurema-preta & $80,98 \mathrm{c}$ & $0,47 \mathrm{c}$ & $18,55 \mathrm{a}$ \\
Pereiro & $84,66 \mathrm{~b}$ & $0,49 \mathrm{c}$ & $14,85 \mathrm{~b}$ \\
Marmeleiro & $87,44 \mathrm{a}$ & $0,29 \mathrm{c}$ & $12,27 \mathrm{c}$ \\
Catingueira & $84,14 \mathrm{~b}$ & $1,64 \mathrm{a}$ & $14,22 \mathrm{~b}$ \\
Mororó & $79,65 \mathrm{c}$ & $1,68 \mathrm{a}$ & $18,67 \mathrm{a}$ \\
Imburana & $84,24 \mathrm{~b}$ & $1,30 \mathrm{ab}$ & $14,46 \mathrm{~b}$ \\
Jurema-branca & $87,52 \mathrm{a}$ & $0,52 \mathrm{c}$ & $11,95 \mathrm{c}$ \\
Mofumbo & $83,15 \mathrm{~b}$ & $1,13 \mathrm{~b}$ & $15,72 \mathrm{~b}$ \\
\hline
\end{tabular}

Médias seguidas da mesma letra, para uma mesma variável, não diferem entre si, pelo teste de Tukey $(\mathrm{p} \leq 0,05)$.

Os resultados observados para o teor de matérias voláteis presente nos briquetes estão dentro da faixa de valores referenciados por Brito \& Barrichelo (1978) para resíduos madeireiros com potencial para serem utilizados em briquetagem, que estão entre $74,10 \%$ e $89,90 \%$. Também estão próximos aos observados por Paula (2010), ao analisar resíduos madeireiros para briquetagem, os quais apresentaram valores para essa variável entre 78,89\% e 83,19\%. O mesmo se pode citar em relação aos valores médios observados por Rodrigues (2010), ao avaliar resíduos de finos de madeira para produção de briquetes, que foram equivalentes a $86,8 \%$.

Considera-se que a presença de materiais voláteis no combustível é uma das principais características responsáveis pelo fornecimento de energia durante a combustão, além de permitir o conhecimento das formas de energia disponíveis no material. No entanto, deve-se considerar que esses compostos possuem a particularidade de promover uma queima muito rápida do combustível. Porém, ao passar pelo processo de briquetagem, haverá maior densificação do material e, consequentemente, redução da área superficial, o que irá colaborar para que a velocidade das reações seja mais lenta, com melhor aproveitamento no tempo de fornecimento de energia pelos briquetes durante a 
combustão. Vale ressaltar, no entanto, a possibilidade de difícil ignição do material ao ser reduzida a área superficial após aumento da densificação.

Paula (2010) encontrou também na análise dos resíduos madeireiros valores entre $0,13 \%$ e $0,18 \%$ e entre $16,66 \%$ e $21,03 \%$ para os teores de cinza e carbono fixo, respectivamente. Rodrigues (2010) observou nos resíduos de finos de madeira valores médios de $0,77 \%$ para o teor de cinzas e de $12 \%$ para o carbono fixo. Observa-se, portanto, que os teores de cinzas encontrados neste trabalho são superiores à média citada na literatura para resíduos madeireiros, com destaque para as madeiras de catingueira e mororó. Os teores de carbono fixo, no entanto, encontram-se acima das médias citadas.

O conteúdo energético do material combustível está expresso também na forma de carbono fixo, o qual se refere à porcentagem do material que queima no estado sólido, enquanto o material residual resultante da combustão está expresso no material inorgânico, a exemplo do teor de cinzas.

Combustíveis com teores mais elevados de carbono fixo são desejados em função das características das reações que ocorrem sob influência desse fator, a exemplo da maior quantidade de energia, normalmente, fornecida sob essas condições, como também, de modo geral, maior resistência térmica do combustível, o que promove uma queima mais lenta. Segundo Pereira et al. (1988), esta característica está relacionada com a estrutura química da lignina presente no material lignocelulósico.

Já o aumento na porcentagem de inorgânicos presentes nos briquetes diminuiu a quantidade de energia desprendida por esse combustível. Esse fato pode ser observado, na maioria das vezes, nos resultados de poder calorífico superior dos briquetes. Verifica-se que os briquetes produzidos com resíduos da madeira de catingueira apresentaram alto teor de cinzas e menores valores de poder calorífico superior, no entanto, o mesmo não foi observado para os briquetes da madeira de mororó, que também apresentou altos teores de cinzas, provavelmente, em função da maior porcentagem de carbono elementar presente no material.

Na Figura 3 são apresentados os valores do poder calorífico superior (PCS) dos briquetes para todos os tratamentos, os quais foram significativos pela análise de variância (teste $\mathrm{F}, \mathrm{p}<0,05$ ).

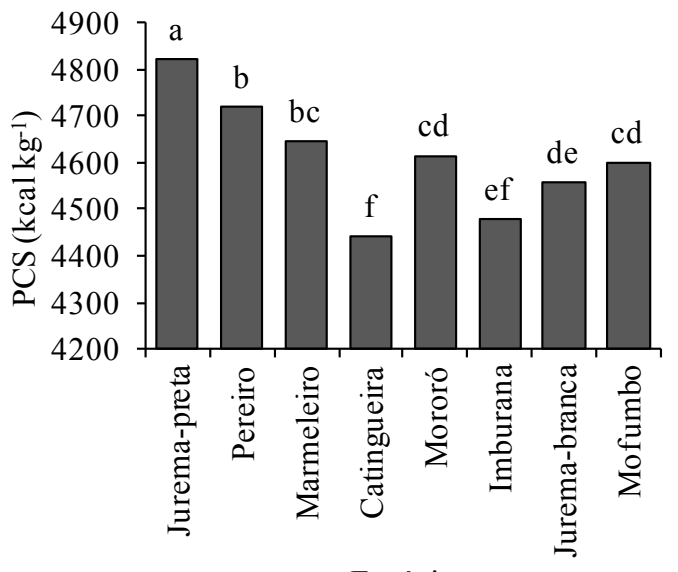

Espécie

Figura 3. Valores médios para o poder calorífico superior dos briquetes confeccionados a partir das oito espécies. Médias seguidas da mesma letra entre as espécies não diferem entre si, pelo teste de Tukey $(\mathrm{p} \leq 0,05)$.

Os valores obtidos para o poder calorífico superior dos briquetes variaram entre 4.442 e $4.823 \mathrm{Kcal} \mathrm{Kg}^{-1}$. Destaque para os briquetes de jurema-preta que apresentaram os maiores valores, enquanto os menores foram observados para os briquetes de catingueira.

Os valores observados neste trabalho são superiores aos encontrados por Silva \& Morais (2008) e Seye et al. (2003), ao estudarem briquetagem em resíduos lignocelulósico que apresentaram valores de PCS de $4.630 \mathrm{Kcal} \mathrm{Kg}^{-1}$ e de $4.234 \mathrm{Kcal} \mathrm{Kg}^{-1}$ para os briquetes produzidos com bagaço de cana e casca de arroz, respectivamente. Brito (1993) cita que a média esperada para resíduos madeireiros está entre $4.000 \mathrm{e}$ 4.800 Kcal Kg-1.

Segundo Rodrigues (2010), a energia liberada por grama do material combustível está relacionada, principalmente, com a sua composição química elementar e com o tipo de ligação química estabelecida entre esses elementos. Assim, possivelmente, os briquetes confeccionados com as madeiras de juremapreta e pereiro apresentaram maiores PCS em função dos maiores teores de carbono elementar e menores porcentagens de oxigênio, visto que a porcentagem de hidrogênio entre os tratamentos não apresentou diferença significativa. Destaca-se, no entanto, que os briquetes de jurema-preta também apresentaram altos teores de carbono fixo. 
Podem ser observados na Figura 4 os valores médios para a resistência à compressão plana (tensão máxima de ruptura) dos briquetes. Para todos os tratamentos, observa-se efeito significativo pela análise de variância (teste $\mathrm{F}, \mathrm{p}<0,05$ ).

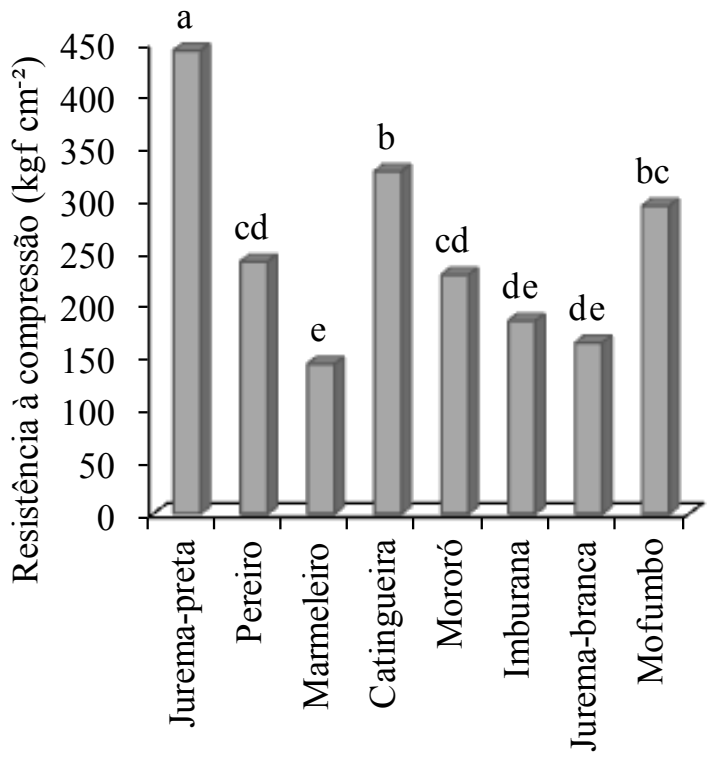

Figura 4. Valores médios para a resistência à compressão plana dos briquetes confeccionados a partir das oito espécies. Médias seguidas da mesma letra entre as espécies não diferem entre si, pelo teste de Tukey $(\mathrm{p} \leq 0,05)$.

Os maiores valores médios observados foram para os briquetes confeccionados com a madeira de jurema-preta $\left(443,33 \mathrm{Kgf} \mathrm{cm}^{-2}\right)$, enquanto os menores foram para os briquetes de marmeleiro $\left(143,33 \mathrm{Kgf} \mathrm{cm}^{-2}\right)$.

Furtado et al. (2010) encontraram valores variando entre 115 e $192 \mathrm{Kgf} \mathrm{cm}^{-2}$ ao estudarem a resistência à compressão plana em briquetes confeccionados com misturas de resíduos madeireiros e também com resíduos puros. Paula (2010) estudou a influência do tempo de compactação na resistência de briquetes de resíduos madeireiros e observou valores variando entre 167,74 e $224,29 \mathrm{Kgf}^{-2}$. A mesma autora, avaliando essa variável em briquetes confeccionados com diferentes resíduos lignocelulósicos encontrou para os briquetes de resíduos de madeira valores médios equivalentes a $190,23 \mathrm{Kgf} \mathrm{cm}^{-2}$.

Vale ressaltar que a força requerida durante o teste de resistência à compressão plana expressa a tensão máxima suportada pelo briquete até o seu rompimento e está relacionada com as forças de aderência entre as partículas do material que o constituem (Kaliyan \& Morey, 2009), e sobre essas, há a significativa influência da razão de compactação do material.

Provavelmente, mesmo a madeira de jurema-preta apresentando maiores valores para densidade básica, o que promove menor razão de compactação no briquete, outros fatores colaboraram para que houvesse melhor acomodação das partículas durante a briquetagem, promovendo assim maior compactação e menor ocorrência de espaços vazios, consequentemente, maior resistência à compressão nos briquetes produzidos com os resíduos dessa madeira.

Carvalho \& Brinck (2004) mencionam que este parâmetro é bastante significativo na avaliação da resistência do briquete ao manuseio, empilhamento, transporte, estocagem, condições de trabalho, entre outros.

Foram encontradas correlações negativas e significativas $(\mathrm{r}=0,972 ; \mathrm{p}<0,05)$ entre as variáveis densidade básica da madeira e o ganho em densidade após a briquetagem. Na Figura 5 é apresentada a equação ajustada entre estas variáveis.

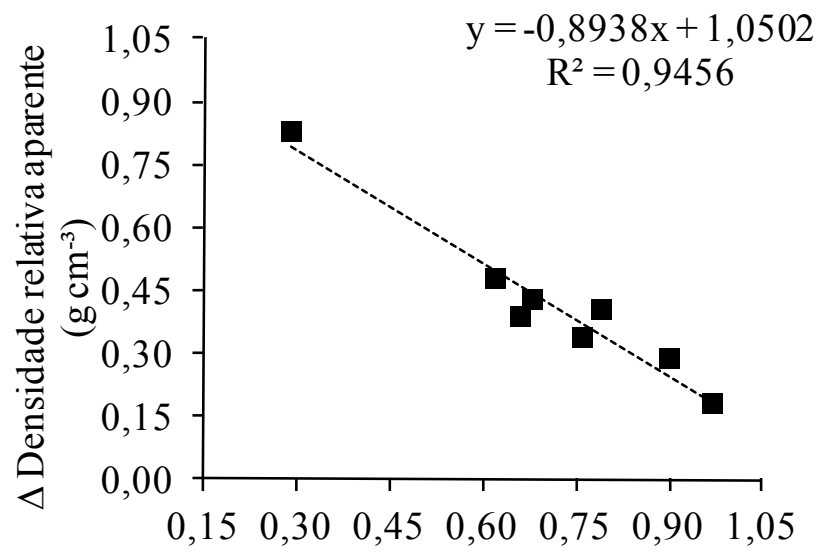

\section{Densidade básica da madeira $\left(\mathrm{g} \mathrm{cm}^{-3}\right)$}

Figura 5. Regressão equivalente às correlações significativas entre a densidade básica da madeira e o ganho em densidade média dos briquetes (eixo Y) confeccionada a partir das oito espécies estudadas.

Observa-se que o ganho em densidade dos briquetes decresce na medida em que aumenta a densidade básica das madeiras das quais foram utilizados resíduos para produção dos mesmos. Estes resultados estão de acordo com os observados por Furtado et al. (2010) ao estudarem o efeito da matéria-prima nas propriedades 
dos briquetes. Segundo os autores, o princípio da razão de compactação aplicada nos briquetes promove a influência significativa da densidade do material de origem sobre a densidade dos briquetes, apresentando-se, de modo geral, inversamente proporcionais.

$\mathrm{Na}$ equação ajustada entre a densidade relativa aparente dos briquetes e sua resistência à compressão plana, foram encontradas correlações positivas e significativas $(\mathrm{r}=0,799 ; \mathrm{p}<0,05)$ entre estas variáveis (Figura 6).

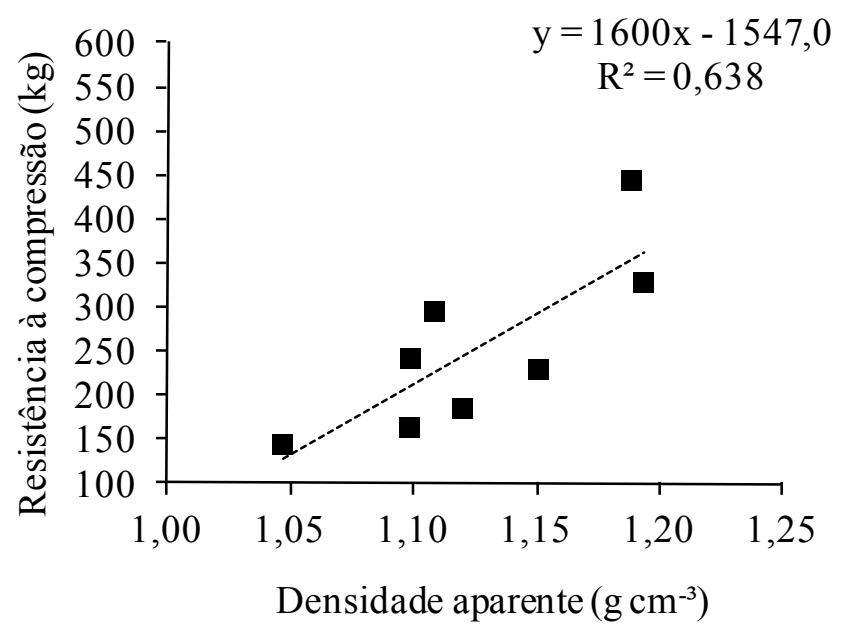

Figura 6. Regressão equivalentes às correlações significativas entre a densidade aparente dos briquetes e a resistência à compressão média das oito espécies estudadas.

Observou-se o aumento na resistência à compressão plana dos briquetes conforme incremento da densidade relativa dos mesmos.

No entanto, vale ressaltar que esses resultados devem ser interpretados com cautela, pois os parâmetros estudados são influenciados pelo tamanho e pela forma dos briquetes, e ainda, por outras propriedades dos materiais a partir dos quais são produzidos. Para muitos propósitos, a densidade é um parâmetro de qualidade mais importante tanto para o material de origem, quanto para o material compactado.

\section{Conclusões}

A faixa de valores observada para a densidade aparente dos briquetes produzidos com espécies do semiárido brasileiro analisadas é considerada satisfatória.

Os briquetes apresentam teores de carbono elementar inferiores aos citados na literatura, no entanto, possuem altas porcentagens de hidrogênio e carbono fixo.
Os briquetesproduzidos com os resíduos das madeiras de mororó e pereiro apresentaram maiores valores para porcentagem de carbono.

Observaram-se baixos teores de enxofre nos briquetes para todos os tratamentos. Os valores médios para os teores de cinzas observados nos briquetes estão acima dos valores citados na literatura, com destaque para àqueles produzidos com as madeiras de catingueira e mororó.

Os briquetes confeccionados com as madeiras de jurema-preta e pereiro apresentaram maiores PCS em função dos maiores teores de carbono elementar e menores porcentagens de oxigênio presentes nos mesmos.

Os briquetes produzidos com a madeira de juremapreta se destacaram em função dos maiores teores de carbono fixo, alto poder calorífico, maior resistência à compressão plana. E os produzidos com os resíduos da madeira de imburana apresentaram os piores resultados para os parâmetros estudados.

Também foi observada correlação negativa entre a densidade básica das madeiras e o ganho de densidade relativa aparente dos briquetes produzidos com os resíduos das espécies do semiárido brasileiro, e correlação positiva entre a densidade aparente dos briquetes e sua resistência à compressão plana.

\section{Agradecimentos}

À Fundação de Apoio à Pesquisa do Estado do Rio Grande do Norte (Fapern), ao Conselho Nacional de Desenvolvimento Científico e Tecnológico (CNPq), à Universidade Federal de Viçosa (UFV) e à Embrapa Florestas.

\section{Referências}

AGÊNCIA DE DESENVOLVIMENTO SUSTENTÁVEL DO SERIDÓ. Diagnóstico do uso da lenha nas atividades agroindustriais do território do serido/RN. Caicó, 2008. 130 p.

AGÊNCIA NACIONAL DE ÁGUAS. Programa de desenvolvimento sustentável e convivência com o semiárido potiguar: relatório de avaliação ambiental (RAA). Natal: Secretaria de Estado de Recursos Hídricos, 2005. 132 p.

AMERICAN SOCIETY FOR TESTING AND MATERIALS. ASTM D2015: standard test method for gross calorific value of coal and coke by the adiabatic bomb calorimeter. Philadelphia, USA, 1982. 
ASSOCIAÇÃO BRASILEIRA DE NORMAS TÉCNICAS. NBR 11941: determinação da densidade básica da madeira. Rio de Janeiro, 2003.

ASSOCIAÇÃO BRASILEIRA DE NORMAS TÉCNICAS. NBR 7190: Anexo B: Métodos de ensaio para determinação das propriedades das madeiras para projetos de estrutura: resistência à compressão. Rio de Janeiro, 1997.

ASSOCIAÇÃO BRASILEIRA DE NORMAS TÉCNICAS. NBR 7993: determinação da umidade da madeira por secagem em estufa quando reduzida à serragem. Rio de Janeiro, 1983.

ASSOCIAÇÃO BRASILEIRA DE NORMAS TÉCNICAS. NBR 8112: carvão vegetal: análise imediata: método de ensaio. Rio de Janeiro, 1986.

BRITO, J. O. Expressão da produção florestal em unidades energéticas. In: CONGRESSO FLORESTAL PANAMERICANO, 1.; CONGRESSO FLORESTAL BRASILEIRO, 7., 1993, Curitiba. Anais... Curitiba: Universidade Federal do Paraná, 1993. v. 3 , p. $280-282$.

BRITO, J. O.; BARRICHELO, L. E. G. Características do eucalipto como combustível: análise química imediata da madeira e da casca. IPEF, Piracicaba, SP, n. 16, p. 63-70, 1978.

CARVALHO, E. A.; BRINCK, V. Briquetagem. In: LUZ, A. B. da; SAMPAIO, J. A.; ALMEIDA, S. L. M. de. Tratamentos de minérios. Rio de Janeiro: Centro de Tecnologia Mineral, 2004. p. 603-636

CORTEZ, L. A. B.; LORA, E. E. S.; GÓMEZ, E. O. Caracterização da biomassa. In: GÓMEZ, E. O. Biomassa para energia. Campinas, SP: Unicamp, 2008. p. 31-62.

FURTADO, T. S.; VALIN, M.; BRAND, M. A.; BELLOTE, A. F. J. Variáveis do processo de briquetagem e qualidade dos briquetes de biomassa florestal. Pesquisa Florestal Brasileira, Colombo, v. 30, n. 62, p. 101-106, 2010. DOI: 10.4336/2010.pfb.30.62.101.

IBGE. Mapa de vegetação do Brasil. Rio de Janeiro: Ministério do Planejamento Orçamento e Gestão, 2004. I mapa, color, Escala 1:5.000.000

KALIYAN, K.; MOREY, R. V. Factors affecting strength and durability of densified biomass products. Biomass \& Bioenergy, Oxford, GB v. 33, n. 3, p. 337-359, 2009.

OVEREND, R. Canada's biomass conversion technology R\&D program. In: JONES, J. L.; RADDING, S. B. (Ed.). Thermal conversion of solid wastes and biomass. Washington, D.C.: American Chemical Society, 1980. v. 130, p. 317-335.

PAULA, L. E. R. Produção e avaliação de briquetes de resíduos lignocelulósicos. 2010. 83 f. Dissertação (Mestrado em Ciências e Tecnologia da Madeira) - Universidade Federal de Lavras, Lavras, MG.
PEREIRA, J. C. D.; STURION, J. A.; FABER, J. Comparação da qualidade da madeira de cinco procedências de Eucalyptus nitens para fins energéticos. Boletim de Pesquisa Florestal, Colombo, n. 16, p.1-6, 1988.

QUIRINO, W. F.; VALE, A. T. do; ANDRADE, A. P. A. de; ABREU, L. S. A.; AZEVEDO, A. C. dos S. Poder calorífico da madeira e de materiais lignocelulósicos. Revista da Madeira, São Paulo, n. 89, p. 100-106, abr. 2005.

QUIRINO, W. F.; BRITO, J. O. Características e índice de combustão de briquetes de carvão vegetal. Brasília, $\mathrm{DF}$ : IBAMA, Laboratório de Produtos Florestais, 1991. 16 p. (IBAMA-LPF. Série técnica, 13).

RODRIGUES, L. D.; SILVA, I. T. da; ROCHA, B. R. P. da; SILVA, I. M. O. da. Uso de briquetes compostos para produção de energia no Estado do Pará. In: ENCONTRO ENERGÉTICO MEIO RURAL 4., 2002, Campinas. Anais... Campinas: AGRENER, 2002. 1 CD-ROM.

RODRIGUES, V. A. J. Valorização energética de lodo biológico da indústria de polpa celulósica através da briquetagem. 2010. 134 f. Dissertação (Mestrado em Ciência Florestal) -Universidade Federal de Viçosa, Viçosa, MG.

SEYE, O.; CORTEZ, L. A. B.; GÓMEZ, E. O. Estudo cinético da biomassa a partir de resultados termogravimétricos. Energia no Meio Rural, Campinas, ano 3, 2003. Disponível em: <http:// www.proceedings.scielo.br/scielo.php?pid=MSC00000000220000 00200022\&script=sci_arttext $>$. Acesso em: 08 jun. 2011.

SILVA, C. A. da. Estudo técnico-econômico da compactação de resíduos madeireiros para fins energéticos. 2007. 68 f. Dissertação (Mestrado em Planejamentos de Sistemas Energéticos) - Faculdade de Engenharia Mecânica, Universidade Estadual de Campinas, Campinas, SP.

SILVA, M. B. da; MORAIS, A. dos S. Avaliação energética do bagaço de cana em diferentes níveis de umidade e graus de compactação. In: ENCONTRO NACIONAL DE ENGENHARIA DE PRODUÇÃO, 28., 2008, Rio de Janeiro. A integração de cadeias produtivas com a abordagem da manufatura sustentável... Rio de Janeiro: ABEPRO, 2008. p. 1-9.

STATSOFT. STATISTICA: data analysis software system: version 8. Porto Alegre, 2009. (Software estatístico).

VITAL, B. R. Métodos de determinação da densidade da madeira. Viçosa, MG: SIF, 1984. 21 p. (SIF. Boletim técnico, 1). 